\title{
HOUSEHOLD WEALTH AND ACCESS TO EDUCATION BY CHILDREN IN DEMOCRATIC REPUBLIC OF CONGO A CASE OF KASONGO DISTRICT
}

\author{
Yves Djuma Idi ${ }^{1 *}$, Dr. Samson NGITAHI ${ }^{2}$, \\ ${ }^{*}$ School of Social Sciences, Master of Arts in Development Studies, Mount Kenya University, Kigali, Rwanda Email: \\ yvesdjuma@gmail.com \\ ${ }^{2}$ Mount Kenya University, Kigali, Rwanda Email: sngitahi@mkurwanda.ac.rw
}

*Corresponding Author: -

Email: yvesdjuma@gmail.com

\begin{abstract}
: -
The purpose of the research was to assess the relationship between household wealth on education of children in Kasongo Districtt. The study objectives were; 1) to analyze the relationship between household income and enrollment rate; 2) to analyze the relationship between household income and rate of completion; 3) to determine the relationship between income, sex and the level of education of household heads, the number school age children, and the sex of the schooled child with education of children in Kasongo District. The study adopted a cross section case-study design with a sample size of 397, using administered questioners and interviewing methods for quantitative and qualitative findings respectively. Guided by human capital and the needs theories, the findings to the study revealed that low income in a household is negatively significant to enrollment of the learners in schools. Results revealed a highly significant relationship between household income and completion rate in primary $(r=0.633, P=0.021)$ but insignificant correlation for secondary school completion rate $(r=0.381, P=0.060)$. The study revealed significant relationship between sex of the household head, education levels of household heads, sex of schooling children and school completion for both cycles $(P<0.05)$. The study concluded that household income significantly relate school enrolment rates for both cycles since the main focus is betterment of the human needs and quality human capital. Upon such, the Government and international partners need to strengthen efforts to reduce poverty and thereby enabling household sources of income for both ends discussed in the two theories.
\end{abstract}

Keywords: Household Wealth, Access to Education, Democratic Republic of Congo

\section{(c) $(\$)$}




\section{INTRODUCTION}

Over the years, the interface between access to education, household wealth and poverty reduction have been proved vital in different countries through research (Schultz, 2016). Whereas education services are easily accessed by wealthier families, the poor struggle to attain a desired level due to complexities associated with tuition. As a signatory of the MDGs as well as SDGs, the DRC embraced access to education by all with the main emphasis of building quality human capital and poverty reduction. However, this did not relieve parents from paying tuition to different primary and secondary schools. In Kasongo District, there has been strong mobilization of household incomes to enable children's enrollment into primary and secondary schools but the incomes remained low. There has been low enrolment and completeness rate of secondary cycle (KaraalpOrhan, 2018).

The relationship between education and low household income therefore compelled this study with the main parameters like parental income, kinship, child-sex and the educational background of the parents. The head of the household, the sex of the head of household, the number enrolled children and those to be enrolled, the distance between the school and child's residence, and the living conditions of the household must be analyzed in order to understand the situation in Kasongo District (Yao, et al., 2016).

\subsection{Objectives of the study \\ 1.1.1 General objective}

The overall objective is to assess the relationship between household wealth on education of children in Kasongo District.

\subsubsection{Specific objectives}

(i) To analyze the relationship between low household income levels and enrollment rate of children in primary and secondary schools.

(ii) To analyze the relationship between low household income and completeness rate of children of primary and secondary schools.

(iii) To determine the relationship between household income, sex and the level of education of household heads, the number of children in school age, the number of schooled children and the sex of the schooled child with education of children in Kasongo District

\section{Review of Literature \\ 2.1 Empirical Literature}

Based on various aspects that when combined make wealth creation a complicated multifaceted phenomenon, the application of this assertion to various households is need to study (Sánchez et al., 2019). One of the assertion has been presented that poverty is the lack of essential materials or product that enhance one wellbeing that mostly include food, shelter and clothing not forgetting other key assets. This however has remained basic in the modern days since various services have been considered essential to the daily living of individual persons. The World Bank Group (2015) shows that poverty can be explained as the lack of important resources that translates to one physically depriving them. It is also worth noting that the poor are also affected psychologically, and they are traumatized especially due their inability to have their voice heard, lack that extends to deprived independence and their vulnerability to exploitation. Their poor states also lead to other abuses including insults, humiliation and rudeness and inhumane types of treatment from various people including those expected to help them.

The destitute also get affected by their inability to fully participate in the community development like in infrastructure development like roads construction and other social activities like weddings and other occasions or rituals that causes social integration problems. Also due to the lack of proper basic infrastructure especially equipped health facilities water, roads the poor extensively suffer as the facilities are quite important. In most cases education considered as a critical aspect of human being that enhances well-being however among the poor it attracts diverse perception and at times considered insignificant and irrelevant among the poor people. The poor in the society also tend to mostly divert their energy on assets instead of income that leads them to associate their human, social, physical, and other environmental related challenges mostly to their vulnerability and high exposure to life risk.

Many writers explain that poverty has multidimensional related social phenomenon on the lives of people (Botha, 2018; Braga, et al., 2017). Voituriez et al. (2017) explains that poverty mostly causes issues related to age, culture, gender and includes other related social and economic related contexts. Authors from both urban and rural areas in Ghana, for instance link men poverty to lack of important material resources and assets, but when it comes to women poverty is perceived to lack of food. The former therefore affects access to education and other services like water, electricity and health. There are also issue that are related to difference in generation whereby the young men from Ghana mainly perceived poverty as the inability to generate income that also translated to issues of lifestyle considering traditional and agricultural.

In most cases, the people's living conditions and location usually affects their status. In the state of Madagascar for instance, farmers are usually associated with poverty and problems like drought while the poor people living in the city are linked to lack of jobs, high cost of products and lack of better trade. It is also associated with limited opportunities to access education services, liberalization of prices, lack of motivation among some people to access both government and private services like health, water and electricity (Karaalp-Orhan, 2018). Poverty is mainly considered as limited ability to access several things that eventually when clustered together results specifically to women lamenting for boiling bananas to feed their children when food is not enough, and when by grace the ministry of agriculture can distributes some corn seeds they cook instead of planting them (Botha, 2018). 
Ironically, they end up borrowing money in order to buy seeds for planting and their problems only increases as they are unable to repay the loans (Latchem, 2014). In place like Armenia, many seasonal changes affect productivity and yields, savings and ability to access quick cash / credit. In many cases, farmers sell their produce when there is an influx of city buyers and at low prices only to re-buy them when they are more expensive due to the need of quick cash as they are unable store their food products or to wait for the prices to get better (Armenia 2006). In place like Guatemala, a Cackchiquel in Indian that mostly works largely as a hired and agricultural employee alluded that for almost a decade, they were affected by serious poverty due to lack of employment.

In societies, there is little hope for the people to have improved lives than what they usually earn. There are several needs which some include the basic needs like food, shelter and clothing which are all hard to access in a situation where poverty has overtaken the possibilities or opportunities to have desired lives (Guatemala 1994a). The limited access to such basics and essentials of life are fundamental towards access to education services that are prerequisite for living an improved life.

\subsubsection{Household income and enrollment rate of children}

Empirical work has shown the link between poverty and education with the main emphasis how poverty hinders access to education services as well as how qualified educated personnel have been influential in the road towards poverty reduction. Qualitative studies from Ethiopia and Ghana show that parents are more likely to send children to work in different areas such as mining areas and fishing than schools (Munir-Kayani et al., 2017). Gregg (2014) discussed parents' attitudes towards children's schooling in a study that used mixed approach of research and emphasized that parents act in an altruistic way towards children by investing heavily in education in order to protect themselves against certain risks at the time of old age. However, there are many parents in Sub-Saharan Africa who think that even without attaining levels of education, children can easily look after them as long as they live and grow in cordial and mutual relationship. Nonetheless, it has remained critical clear that when women increase their investment in human capital and enter the labor market, the opportunity cost of raising a child increases and such females have high propensity to look after their parents 100 times.

In yet another study conducted from Burkina Faso, Hong et al. (2016) show that schooling is ascertained by living standards. Indeed, the socio-economic factors are the main determinants to schooling children in cities in both cities and rural areas. It was also highlighted that among the social economic factors; religious or ethnic differences, the homestead environment, education levels of parents, the wealth or poverty status of a family are among important determinants towards a child's effort to access education services at all levels. The scholars affirm that despite the current wave to free education services at primary and secondary levels in most schools in Africa, the wealth / income or poverty status of parents has remained significant factor towards children's access of education services.

In a quantitative study, Bukuluki and Mubiru (2013) added that the household heads with higher socioeconomic status have always struggled to assist their children to enroll into certain schools; and prepare the succession to their household apparatus as best they can. Conversely, the social groups with limited incomes can only offer incomplete or poor educational conditions to their children. Under these conditions, even if the benefits to upper class were eliminated by taxation, the subsidy of the education of the poor or paying school tuition by the rich parents remains the main force towards the successful education acquisition.

According to Voituriez, et al., (2017), the social environment of the child is a key element for enrollment, keeping in schools and successful acquisition of education levels. This statement is valid for most countries in the South and SubSaharan Countries in particular. Three types of family environments have been discussed in relation to access of education services. Using a mixed method of research, Pender et al. (2019) show that parents invest in schooling of their children, who present a minor challenge to studying. Among such groups, standard of living and educational level of the parent (s) appear to be decisive in their commitment to their children's schooling, the financial as well as temporal cost of this investment is likely to be less important when the income or education level of the children-parents are higher. Parents whose financial constraints are not too strong mobilize tuition for their children successfully and give them lessons to grow up responsibly in according to use of financial resources in future; all these are essential in contributing to their success (Karagiannaki, 2012).

Another group of parents do little or less to invest in their children and neglect interest of getting involved in schooling of their children. Karagiannaki (2012) had stated that such parents fail to raise moral upright children and have been the main cause to the failures of their children which they have never admitted to be the main cause. In particular, the lack of investment of the head of the family in the schooling of the children and the consequent failure to provide moral information discourage them to opt for various paths that never support their success in education.

Pender, et al., (2019) state that the last category of parents has been those who are forced to educate their children in bad conditions or unable to continue their schooling. These are mostly parents in rural areas whose conditions are inherited from their grand-parents whose ideal to education has never been supportive or increasing positively to the end. In the rural areas where they live, schools have been established by the government or individuals with goodwill but such parents have never seen the efficacy of education to their causal environment. The fact that they are not educated, their approach towards education has also remained low and not interested in education of their children. Besides, their level of income is low due to limited ownership of resources as sources of income, supportive in accessing education services.

However, household characteristics, low income and unfavorable family climate conditions and precarious housing conditions are not the only factors contributing to enrollment of children in schools. In fact, whereas the home factors do contribute to failures in enrollment, research has also found that this has been attributed by the influence of a school environment that is unsuited to the perceptions and attitudes of the parents, community and the children. 


\subsubsection{Household income and completeness rate of children}

The wealth or income of the household has been one of the cardinal factor to the rate of children completing education in various ways. This has been found in various literature, although the misuse of such income can also significantly negatively affect the completion rate. In a study conducted from Ghana, the financial resources or income of parents significantly influences schooling years of a child as well as completion time (AniAsamoah Marbuah, 2016). The study established that it is financial resources or income that have been essentially responsible to certain decisions where to allocate or construct houses. The income or wealth of a household also influence on the number of children to be produced due to proper upbringing, ability to access and complete education levels. Drajea and O'Sullivan (2014) remarked that household size and place of residence were also shown to having negative significant influence on years of schooling in Uganda.

In a study conducted from the rural Uganda by Drajea and O'Sullivan (2014), a statistical positive significant relationship between parents' income and quality of support towards completion rate of education was found. The wealth of household is a strong predictor of educational enrollment, schooling life and completion rate. In this study, a quasi-design was applied in which mixed methods of research were used to collect data about parents' household incomes and children's outcomes. Results revealed that a yearly increase of $\$ 4000$ for the poor families in income has a proportionate increase in educational attainment to a student aged 21.

In United Kingdom, ethnographic research in which Blanden et al. (2012) immersed into the conditions of both minors, colored and English race was carried out to establish the rate of completing levels in education and household incomes. Results of the study revealed a positive significant relationship between income and completion rate among the English communities. The study further revealed that children from richer families were the only education beneficiaries as compared to the minors and coloreds from China, India and South American countries. In yet another study in which the main investigator used quantitative and qualitative yet starting with qualitative, parents' education was also found significantly related to rate of completing education in the UK (Jonathan, 2012). The study found that most educated parents take time to teach their children while at home and this could not take place among parents with limited education. The study further showed that parents who had attained high level of education are supportive, encouraging and gave children time to revise that uneducated groups that could always encourage their children into plays, and singing.

Harmon and Walke (2017) used time series analysis in education to assess factors related to rate of completion of education among students of secondary and primary schools in the UK or Common Wealth Nations. In this study, a correlation design was adopted for various variables like household income and rate of completion among children. The study did not only find household income positively significant to the rate of completion only, but also on the early days of to enroll to school. The study also found that household income or wealth is related to various variables that are essential in students' life like the timely enrollment, enough and appropriate scholastic materials to use at all levels, timely payment of tuition, enough dressing and confidentiality of timely finishing of education.

In another study conducted from UK by Blanden and Gregg (2014) using qualitative and quantitative methods of research, a cross-section design on 2224 school going students was conducted. The findings revealed that educational attainment was significantly influenced by household wealth. Correlation was also made and educational attainment remained significantly influenced by household income at regression analysis. Nonetheless, Lauer (2012) conducted yet another study and it was found that household wealth / income has negative effect to educational attainment as revealed that household income had a weak relationship with child's educational achievements. Such situation was found among SubSaharan Africa and areas neighboring the lakes where children are sources of labour despite sources of income. It was qualitatively found that children spend limited time reading at home as they dedicate much of their time and labour to activities generating income for their household. This applies to children living in slums with their mothers or guardians. According to Washbrook et al. (2014), poor children were found disadvantaged in education at age 7 to 9 in Germany.

\subsubsection{Other social-economic variables and access to education}

There are various studies which have concentrated on gender equity in education and females have been found to be seriously disadvantaged when it comes to educational attainment (Spitzer et al., 2013). Confounded by a variety of factors, girls have been severely affected by cultural and traditional beliefs in which women are thought to take care of the family roles by helping their mothers in the process of food preparation. A study conducted by Sida (2017) indicated that gender determines whether a child attends or remain in school and poor girls have been found to have the lowest educational attainment in the world. This has been supported by Christina (2017) who found that there was a great different between female and male access and attainment of education in most households of Sub-Saharan Africa. In a study conducted by Mensah and Kiernan (2010) using qualitative methods of research, it is revealed that lower attainment in communication, language and literacy and mathematical development for both boys and girls in families experiencing socio-economic disadvantage was revealed. However, there is no study conducted referring to household head education level and its effect on child education attainment and also gender did not impact scores.

Angrist and Krueger (2012) found a significant relationship between child's age at entry in school with educational attainment. A study conducted at the University of Chicago revealed that there was a significant relationship between educational attainment and age of the student (Tom, 1997). According to Voyles (2011), the relationship between student age and achievement on a state mandated assessment for a cohort of North Georgia elementary school students in their first, second, and third grade years revealed that student age did not influence academic scores. 


\subsection{Research Gap}

In the theoretical analysis of poverty, it is clearly established that there are various approaches that have been comprehensively used than the normative monetary approach when addressing poverty issues. This study is thus part of among various studies carried out to understanding the link between poverty and access to education; and the extent to which poverty hinders growth of human capital in any nation. In various studies across the globe, it is clearly demonstrated that there is a negative link between poverty levels and access to education. The fact that some households are presented poor, their family members have limited access to sources of income yet education services are rendered at a cost. The low-income households tend to send their children to various casual works rather than to schools. This hinders the growth of human capital as children dropout at an early age. It should also be pointed that the monetary poverty aspect that is mostly evaluated by the international community and the World Bank; has various factors that influence access to education for children, including gender and other variables presented in this work. These among others have continued posing challenges to growth and development of human capital among population in both peri-urban and rural areas.

This study aligns with the design that assess poverty as the major constraint towards attainment of basic needs (food, water and accommodation). The availability, affordability, accessibility and usability of the basic needs have been mainly constrained by poverty leaving the poor people at the mercy of rich individuals who always exploit them. Aware of this situation, governments have come up with various approaches like universal education but such have fallen short to the intended purposes since most government schools lack facilities and renaturation of teachers remains worst challenge to governments. The factor that monetary design reduces poverty and aware that educated persons forge the way to accumulate incomes, poor people fall short in accessing education services as compared to rich whose sources of income have remained stable for a long period of time.

\section{Materials and Methods}

Research used a cross-sectional case study design. It was conducted using survey questionnaires. Therefore, numerical was got. In short, the study applied quantitative method approach of research which involves collecting and analyzing data to predict variables (Almalki, 2016). This method was based on deductive positivistic paradigm that focuses on testing and proving of hypotheses (Regnault, et al., 2018). The target population for this work was 55415 households which have the children in primary and secondary level in Kasongo District. A sample size of 397 households was used and this was determined using the Yamane (1967) formula. The study used random sampling technique in order to select participants to this study. This was especially data from the key informants which was collected through narratives and transcribed. Content analysis was done basing on the objectives of the study and in attempt to answer the subsequent research questions.

The quantitative data which were organized and entered into Microsoft Excel were later imported into SPSS and AMOS for analysis. The analysis was done per objective. For the objective one about low households' income and the enrollment rate of children, analysis was done using the liner regression analysis with the major intent to establish the nature of relationship between independent and dependent variable. The Pearson Correlation Coefficient was run for the inferential statistics to establish the strength of the association of low income and rate of completion of primary and secondary schools. The value between -1 to +1 , where a 0 value shows no relationship and a value greater than 0.8 indicates a high correlation according to Sekeran (2003) was used to determine the level of association. Analysis for the objective three underwent two process before the final results. The first process was exploratory analysis for standardizing the variables and confirmatory analysis.

\section{Research Findings}

\subsection{Relationship between household income levels and enrollment rate}

One of the objectives of the study was to analyze the relationship between household income levels and enrollment rate of children in primary and secondary schools. Participants were tasked to rate the rate of enrollment in Kasongo District for both secondary and primary levels; and reults are presented in Bar - Chart 4.1.

\section{Bar-Chart 4.1: Ranking enrollment rate in Kasongo District}

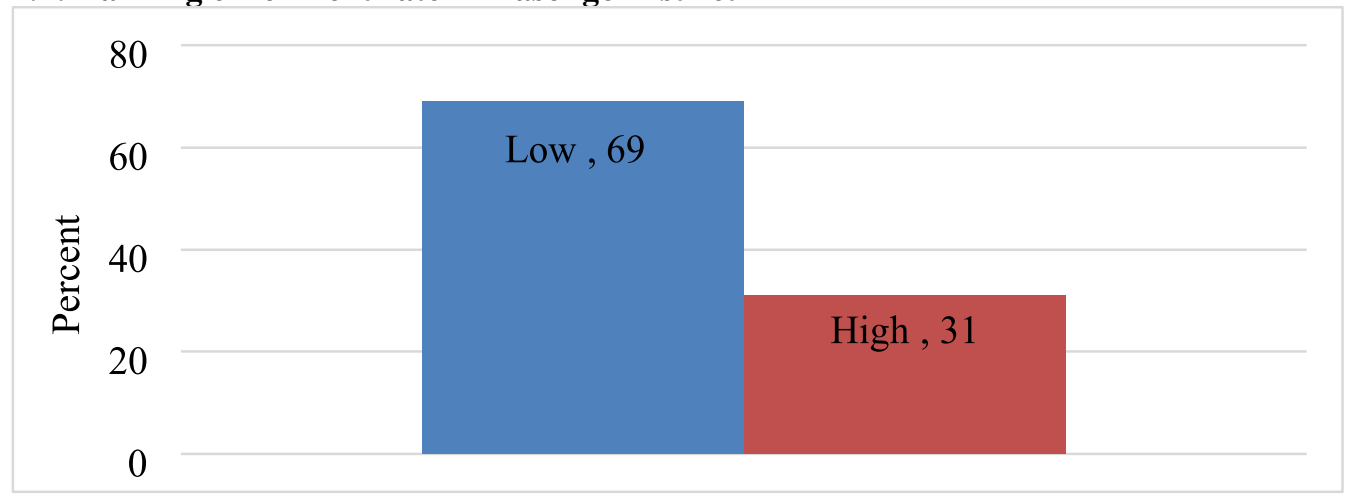

Bar-Chart 4.1 shows that $69 \%$ of the participants agreed that enrolment of the students in both ordinary and primary education was low yet $31 \%$ ranked enrolment as high. The study established that the main factor has been due to low incomes of the people especially parents who do not have sources of income apart from crop farming. The key informant 
noted that a few groups of parents with birds and cattle sale them for other reasons than enrolling children to school. The situation was ranked worse in families with girls as compared top boys as one of the key informants asserted that "in Kasongo District, where a boy tends to reach in education, it is hard for a girl to aspire. Only boys have been considered influential in the different families and this has affected attitude to education among them." The effect of low incomes on the enrollment of the students in Kasongo District is presented in Table 4.5

Table 4.1: Effect of income on enrollment to school

\begin{tabular}{|c|c|c|c|c|}
\hline Variables & $\begin{array}{l}\text { Strongly } \\
\text { agree }\end{array}$ & Agree & Not sure & Disagree \\
\hline $\begin{array}{l}\text { Low incomes have reduced enrollment to } \\
\text { schools }\end{array}$ & $156(46.8 \%)$ & $65(19.6 \%)$ & $44(13.2 \%)$ & $68(20.4 \%)$ \\
\hline Low incomes makes students overstay at home & $109(32.7 \%)$ & $135(40.6 \%)$ & $79(23.7 \%)$ & $10(3.0 \%)$ \\
\hline $\begin{array}{l}\text { Low incomes makes learners start schooling at } \\
\text { an old age }\end{array}$ & $196(58.9 \%)$ & $110(33.0 \%)$ & $27(8.1 \%)$ & $0(0.0 \%)$ \\
\hline $\begin{array}{l}\text { Low incomes makes some parents fail to send } \\
\text { children to school }\end{array}$ & $65(19.5 \%)$ & $90(27.0 \%)$ & $35(10.5 \%)$ & $143(43.0 \%)$ \\
\hline
\end{tabular}

Source: Primary Data, 2021

Results presented in table 4.1 indicates that reduced enrollment to school among the people of Kasongo District. According to response, it is indicated that $46.8 \%$ of the participants strongly agreed, $19.6 \%$ agreed; $13.2 \%$ were not sure and $20.4 \%$ disagreed. Participants were able to explained that the main reason for lacking sources of income as too much expectation from the government since they all believe that the DRC government has got mineral resources that could accrue revenue to support the people from poverty. The key informants noted that there is much perception that the government should be supportive to its people especially in basic and specific services like education, health and water. Such perceptions among the people have been the main factors leading to lack of sources of income.

The study also established that low incomes has been responsible for the long stay of young people at home despite having reached the age to be initiated to school. In accordance to Table 4.5 , it is presented that $32.7 \%$ strongly agreed; $40.6 \%$ agreed; $23.7 \%$ were not sure and $3.0 \%$ disagreed. The key informants noted that there are many persons who report to school at an old age to start primary level. However, such old age is susceptible to dropout from school after starting or at later stage. The study established that some older persons find it impossible to cope up with the young people in the same class as they shy away studying with the young ones. The key informants went ahead to assert that there are various activities that children always do as they stay home in the due course.

Table 4.1 also indicate that low incomes is the leading cause for the children to start education or primary education at late age yet the age when to start is well known by their parents. On strongly agree with the statement, they were 58.9\%; and $33.0 \%$ on agreeing. Lastly, the study found that low incomes among parents in Kasongo District at times make parents fail to send their children at school.

4.2 Analysis of low incomes and enrolment to school

In order to analyses the relationship between low incomes and enrollment to schools, a linear regression model was run and results are presented in Table 4.2.

Table 4.2: The Linear Regression Model for low incomes and enrolment to schools

\begin{tabular}{|c|c|c|c|c|c|}
\hline \multirow[b]{2}{*}{ Model } & \multicolumn{2}{|l|}{ Unstandardized Coefficients } & Standardized Coefficients & \multirow[b]{2}{*}{$t$} & \multirow[b]{2}{*}{ Sig. } \\
\hline & $\mathrm{B}$ & Std. Error & Beta & & \\
\hline & (Constant) & 2.168 .110 & & 19.735 & .000 \\
\hline & $\begin{array}{l}\text { Low income has reduced enrollment to } \\
\text { schools }\end{array}$ & $-.115 \quad .019$ & -.296 & -6.025 & .000 \\
\hline & Low income leads overstay at home & $.154 \quad .026$ & .277 & 5.993 & .000 \\
\hline & $\begin{array}{l}\text { Low incomes leads starting schooling at an } \\
\text { old age }\end{array}$ &.$- .333 \quad .033$ & -.463 & 10.117 & .000 \\
\hline & $\begin{array}{l}\text { Low incomes fail parents to gend children } \\
\text { to school }\end{array}$ & $-.156 \quad .018$ &. .404 & -8.902 & .000 \\
\hline
\end{tabular}

Dependent Variable: Rate of enrollment to primary and secondary levels Source: Primary Data, 2021

As presented in Table 4.6, there is a negative significant relationship at p-value of .000 between low incomes among parents and enrollment to primary and secondary schools. This has therefore been experienced in Kasongo District, DRC. The ANOVA factor Model justifying the significant relationship is presented herewith.

Table 4.3 Analysis for Variance (ANOVA)for low incomes and enrolment to schools

\begin{tabular}{llllll}
\hline Model & Sum of Squares & df & Mean Square & F & Sig. \\
\cline { 1 - 6 } $1 \quad$ Regression & 29.781 & 4 & 7.445 & 59.598 & $.000^{\mathrm{b}}$ \\
Residual & 40.975 & 328 & .125 & & \\
Total & 70.757 & 332 & & & \\
\hline
\end{tabular}

a. Dependent Variable: Rate of enrollment for primary and secondary levels 
b. Predictors: (Constant), Low incomes makes some parents fail to send children to school, Low incomes makes students overstay at home, Low incomes makes learners start schooling at an old age, Low incomes have reduced enrollment to schools

Source: Primary Data, 2021

As indicated in ANOVA modeling, the relationship between low income and rate of enrollment is significant. Predictors in this modeling are predictors at $.000^{\mathrm{b}}$ towards rate of enrolment for primary and secondary levels.

\subsection{Relationship between household income and completion rate}

The second objective sought to establish relationship between income and student's rate of completion of primary and secondary school. The findings to this study have been presented in Table 4.7; starting with the extent to which low income delayed learners' completion levels. In accordance to the table, $47.4 \%$ of the participants strongly agreed; $46.2 \%$ agreed and 6.4\% were not sure. From the key informants, the study established that due to low income by parents, learners could not feel confident that they would complete education levels. This in turn contributed to poor academic performance of the learners. It was also mentioned that right from the beginning of the levels, learners have doubting mind towards completion. This has been energized by daily parents' confrontation towards learners to absentee him/herself to assist in the home activities. This contributed to absenteeism from school.

Table 4.4 Low income and rate of completion of school

Source: Primary Data, 2021

\begin{tabular}{llll}
\hline Variable & Strongly agree & Agree & Not sure \\
\hline Low income delays learners' to complete levels & $158(47.4 \%)$ & $154(46.2 \%)$ & $21(6.4 \%)$ \\
Low income increases absenteeism & $145(43.5 \%)$ & $128(38.5 \%)$ & $60(18.0 \%)$ \\
Low income discourages students daily schooling & $228(68.5 \%)$ & $76(22.8 \%)$ & $29(8.7 \%)$ \\
Low income undermines learners' integrity & $213(64.0 \%)$ & $91(27.4 \%)$ & $29(8.6 \%)$ \\
Low income creates inferiority among learners & $105(31.5 \%)$ & $187(56.2 \%)$ & $41(12.3 \%)$ \\
\hline
\end{tabular}

In fact, $43.4 \%$ of the participants strongly agreed that low income increase learners' absenteeism; $38.5 \%$ agreed and $18.0 \%$ were not sure. It was also found that low income discourages students' daily schooling as justified by $68.5 \%$ who strongly agreed; $22.8 \%$ agreed and $8.9 \%$ was not sure. The correlation analysis between household income and rate of completion of children in primary and secondary schools in Table 4.5.

Table 4.5: Correlating household income and rate completion of children

\begin{tabular}{|c|c|c|c|c|}
\hline & & $\begin{array}{c}\text { Income } \\
\text { level }\end{array}$ & $\begin{array}{c}\text { Primary completion } \\
\text { rate }\end{array}$ & $\begin{array}{c}\text { Secondary } \\
\text { completion rate }\end{array}$ \\
\hline \multirow[t]{3}{*}{ Income level } & Pearson Correlation & 1 & .633 & .381 \\
\hline & Sig. (2-tailed) & & .021 & .060 \\
\hline & $\mathrm{N}$ & 3251 & 4926 & 4926 \\
\hline \multirow{3}{*}{$\begin{array}{l}\text { Primary } \\
\text { completion rate }\end{array}$} & Pearson Correlation & .633 & 1 & .254 \\
\hline & Sig. (2-tailed) & .021 & & .145 \\
\hline & $\mathrm{N}$ & 4926 & 4810 & 4810 \\
\hline \multirow{3}{*}{$\begin{array}{l}\text { Secondary } \\
\text { completion rate }\end{array}$} & Pearson Correlation & .381 & .254 & 1 \\
\hline & Sig. (2-tailed) & .060 & .145 & \\
\hline & $\mathrm{N}$ & 3251 & 4810 & 4810 \\
\hline
\end{tabular}

Source: Primary Data, 2021

As indicated in Table 4.5, results revealed that the income level of the child household is significantly related to completion rate and this is justified by a high Pearson value and a significant $\mathrm{P}-$ Value $(\mathrm{r}=0.633, \mathrm{P}=0.021)$. As illustrated in Table 4.8 further, income level has no significant relationship with completion rate in secondary school ( $\mathrm{r}=0.381$, $\mathrm{P}=0.060$ ). This implies that household income from which the secondary child would come from did not influence his/her capacity to complete the levels.

\subsection{Prediction between other socio-economic variables}

For the Student's test, the confirmatory test analysis of the explanatory variables (sex, level of education of the household head, number of school-age children, number of children attending school, sex of the child attending school) significantly relate to completion rate. Probabilities found at the 95\% confidence level are less than 5\%. For Fischer, such models are globally significant if the probability reads 0.0000 or less than $5 \%$. 
Table 4.6: Empirical interpretation

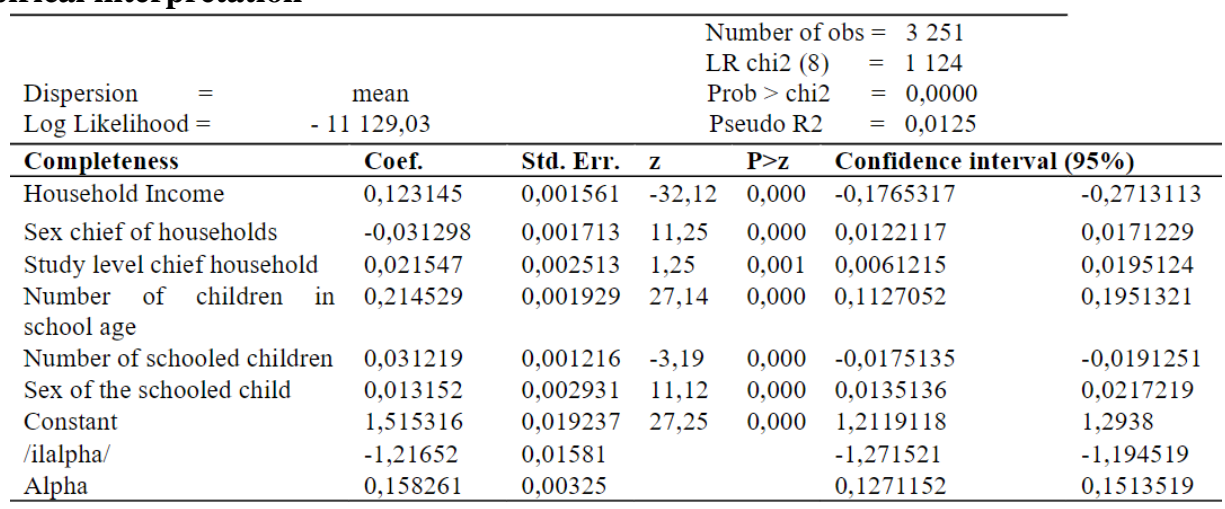

Source: Primary Data, 2021

The estimates made on the data collected from households allowed us to relate household poverty rate of school completing schools. To do this, we highlighted poverty and income, sex of the of household heads, the level of education of household heads, the number of children in school age, the number of schooled children and the sex of the schooled child. Based on the estimation of the negative binomial model in the table above, the household income, the sex of the household head, the number of children in school age, the number of schooled children and the sex of the schooled child negatively influence the completeness of schooling more at primary than at secondary level. On the other hand, the study level of the head of household positively influences the level of school completeness for both cycles. Finally, in Kasongo District, male-owned households have a high completeness rate than those held by women.

\subsection{Discussion of Findings}

This section presents the discussion of the findings as presented in chapter four. The discussion has been presented in line with research questions and with the literature that has been used to identify the gaps. It is noble to highlight that the existence of poverty within the family background is dire towards the human basic needs as presented in the hierarchy of needs by Maslow. Water, food and accommodation are the basic needs as presented on the basement of the pyramid and the failure to achieve such restrain the road to education which is a source of human capital. The human capital theory as used to underpin this study is therefore a result of the basic needs theory by Maslow. Therefore, correlating household's income with enrollment and rate of completion, is an approach rotating within what Maslow developed in his theory. Although there is no specified and internationally recognized year for enrolling of children to schools, education has remained one of the rights to children across the globe. It is a right which governments committed themselves to achieve and to make sure that children enroll to school at young age in attempt to have quality human capital. The foundation to all these is the home where children are born from, grow and work to achieve the best in their lives. Considering the nature of African families and aware that this study assessed the relationship between household income levels and enrollment rate of children in primary and secondary school results indicated that revealed that the income level of the child household significantly impacted on enrolment rate in primary and secondary school.

These results are in agreement conducted by (Githinji, 2012) in Kenya that revealed that child's parents' income impact on enrolment rate in primary schools and the number of years stayed in school but a study in Burkina Faso was in contradiction with the study findings after revealing that household income underestimate primary school enrolment (Grimm, 2019). A study by Iddrisu, (2016) was in agreement with the study findings but the difference is that the effect of income level on children enrolment was dissociated into three categories that is its effect on male and female enrolment and it was found that income levels effected the enrolment of girls higher than boys. Deolalikar (2014) study in Kenya revealed a positive association between primary child school enrolment and household income but Swinnerton (2016) revealed that household poverty has no influence on primary enrolment. Deng and Sherraden, (2012) in agreement with the study findings revealed that asset ownership significantly impacted on primary school enrolment. Household income was found to significantly affect the enrolment of boys and girls with more effect on boys than girls which contradicts with the study findings. Primary school enrolment was found to be insignificantly impacted by parents' labor force participation of parents indicating that when parents are working, there is financial liberty and children are likely to be enrolled in school. Sackey, (2017) study revealed that parent's resources significantly impacted the enrolment of secondary school students meaning that secondary educational attainment is financed through household resources such as farms, businesses that generate income for school fees payment.

For the correlation between household income and completeness rate of children of primary and secondary schools' results revealed that income level of the child household significantly impacted on completion rate in primary school and insignificantly impacted on completion rate in secondary school. These findings are in agreement with Marbuah (2016) study in Ghana that revealed that financial resources of parents significantly influence school grade completion. Furthermore, the study findings concur with a study by Drajea and O'Sullivan (2014) in rural Uganda, that found a statistically significant relationship between parents' income and quality of support to their children's education. Blanden and Gregg (2014) study in Britain also agreed with the study findings after revealing that educational attainment was significantly influenced by household wealth. However, Lauer (2012) study found out that household income had a weak 
relationship with child's educational achievements in Germany (Washbrook et al., 2014). For the correlation between sex of the child, level of education of household heads, age of the child and sex of the household head with educational attainment, results revealed that sex of the household head, study level of the head of household and the sex of the schooled child positively influences the level of school completeness for both cycles. These results are in agreement with (Spitzer et al., 2013) who revealed that gender equity in education seriously affects educational outcomes (Spitzer, et al., 2013). According to Christina (2017), it is indicated that gender determines whether a child attends or remain in school and poor girls have been found to have the lowest educational attainment in the world. Mensah and Kiernan (2010) revealed that lower attainment in communication, language and literacy and mathematical development for both boys and girls in families experiencing socio-economic disadvantage was revealed. However a study conducted by Angrist and Krueger (2012) revealed a significant relationship between child's age at entry in school with educational attainment which is in contradiction with the study findings but Voyles (2011) study that examined the relationship between student age and achievement on a state mandated assessment for a cohort of North Georgia elementary school students in their first, second, and third grade years revealed that student age did not influence academic scores which agrees with the study findings.

\subsection{Conclusion}

As indicated from the findings, it is revealed that the income level of household significantly relates to completion rate in primary school as evidenced by a high Pearson value and a significant $\mathrm{P}-$ Value $(\mathrm{r}=0.633, \mathrm{P}=0.021)$. However, it is presented insignificant towards completion rate in secondary school $(\mathrm{r}=0.381, \mathrm{P}=0.060)$. This implies that household income from which the secondary child comes from does not influence his/her capacity to enroll for secondary education The analysis focuses on statistically significant control variables. In the model developed, except for the marital status of the head of household, all other variables in the model are statistically significant at the $1 \%$ level, all things being equal. The econometric model above shows a negative correlation between the level of household income and the level of enrollment and completeness school of children. In fact, when household income increases, the enrollment and completion rate tend to increase for the household concerned. The coefficient of the gender variable of the head of household has a positive sign and reflects the existence of differences between male and female household heads in school monitoring of children in Kasongo. In fact, children from households headed by men have a more complete completeness rate than children from female-headed households. Similarly, the coefficients of the variables number of school-age children is positive and indicates a statistically significant increase in the completeness rate when the number of schoolgoing children in the household decreases and vice versa.

\subsection{Acknowledgement}

This laborious research would not have been successfully completed without the help of several people who in one way another facilitated to the completion of the work. Firstly, I would like to extend my sincere gratitude and heart-felt appreciation to my Almighty God, to whom I owe my life, wisdom and good faith in all endeavors. I praise him for enabling me on my academic journey and in carrying out this academic research. I also would like to thank Mount Kenya University staff particularly the lecturers in the Department of Social Sciences for guidance and support throughout my studies. I am also indebted to my family and friends; especially to my beloved wife Marie Desanges Kavira and my children Kevinnes Djuma, Joyce Djuma M., Barack Djuma M. and Ingrid Djuma N. and classmates for their support in one or on other way; I will always cherish their love and encouragements towards me. Finally, I owe sincere thanks to all my respondents, classmates and fellow colleagues.

\section{References}

[1].Angrist, J. D., \& Krueger, A. B. (2012). The effect of age at school entry on educational attainment: An application of instrumental variables with moments from two samples. Journal of the American Statistical Association, 87(418), 328-336. https://doi.org/10.1080/01621459.1992.10475212

[2].Ani-Asamoah Marbuah, D. (2016). Influence of parental income and educational attainment on children's years of schooling: case of ghana. Institutionen För Pedagogik, Didaktik Och Utbildningsstudier Department of Education, 1, 39. http://urn.kb.se/resolve?urn=urn:nbn:se

[3].Blanden, J., \& Gregg, P. (2014). Family Income and Educational Attainment: A Review of Approaches and Evidence for Britain. CMPO Working Paper Series No. 04/101, 2(04), 56-67.

[4].Blanden, J., Gregg, P., \& Machin, S. (2012). Education and family income. Child Development, 2(1), 0-43.

[5].Botha, F. (2018). The impact of educational attainment on household poverty in South Africa. Acta Academica, 2(3), 23-29.

[6].Braga, B., Mckernan, S., Ratcliffe, C., \& Baum, S. (2017). Wealth Inequality Is a Barrier to Education and Social Mobility. Opportunity and Ownership Initiative, 1(4), 45-56.

[7].Bukuluki, P., \& Mubiru, J. (2013). the Status of Social Security Systems in Uganda: Konrad Adenauer Stiftung, 2(4), 45-67.

[8].Christina, (2017). Gender and Educational Attainment Gender. Sida, 12(2), 567-678.

[9].http://fawe.org/activities/interventions/COEs/rwanda/index.php

[10]. Deng, S., \& Sherraden, M. (2012). Household Assets, School Enrollment and Parental Aspirations for Child ren's Education in Rural China Does Gender Matter? Household Assets, School Enrollment and Parental Aspirations for Children' s Education in Rural China: Does Gender Matter? CSD Working Papers, 1(12), 12-39. 
[11]. Deolalikar, A. B. (2014). The Determinants of Primary School Enrollment and Household Schooling Expenditures in Kenya: Do They Vary by Income? Department of Economics, University of Washington, 1(2014).

[12]. Drajea, A. J., \& O'Sullivan, C. (2014). Influence of parental education and family income on children's education in rural Uganda. Global Education Review, 1(3), 149-166.

[13]. Githinji, J. M. (2012). Impact of family income on participation in primary education in buuri district, meru county. Unpublished Master's Thesis Kenyatta University, 1(11), 123-234.

[14]. Gregg, P. (2014). Family Income and Educational Attainment: A Review of Approaches and Family Income and Educational Attainment: A Review of Approaches and Evidence for Britain. Oxford Review of Economic Policy, 1(6), 78-90. https://doi.org/10.1093/oxrep/grh014

[15]. Grimm, M. (2019). Does Household Income Matter for Children's Schooling? Evidence for Rural Sub-Saharan Africa. Forthcoming in Economics of Education Review, 30(4), 740-754.

[16]. Harmon, A. C. C., \& Walke, V. O. I. (2017). the impact of parental income and education on the schooling of their children. Journal for Economic Educators, 1(12), 30-39.

[17]. Hong, R., Banta, J. E., \& Betancourt, J. A. (2016). International Journal for Equity in Relationship between household wealth inequality and chronic childhood under-nutrition in Bangladesh. International Journal for Equity in Health, 10(2), 1-10. https://doi.org/10.1186/1475-9276-5-15

[18]. Iddrisu, A. M. (2016). The Effect of Poverty, Household Structure and Child Work on School the Effect of Poverty, Household Structure and Child Work on School Enrolment. Journal of Education and Practice, 6(6), 23-34.

[19]. Jonathan, (2012). The Relationship Between Childhood Family Income, Educational Attainment and Adult Outcomes. Un Published Master's Thesis Makerere University, 1(2), 567-590.

[20]. Karaalp-Orhan, H. S. (2018). The Impact of Gender-Specific Human Capital on Economic Growth: An

[21]. Empirical Investigation for Turkey. Zagreb International Review of Economics and Business, 21(s1), 15-30. https://doi.org/10.2478/zireb-2018-0021

[22]. Karagiannaki, E. (2012). The effect of parental wealth on children's outcomes in early adulthood. Centre for Analysis of Social Exclusion London School of Economics Houghton, 1(8), 91-101.

[23]. Latchem, C. (2014). Informal Learning and Non-Formal Education for Development Maximizing Human Potential. Journal of Learning, 1(2), 45-60.

[24]. Lauer, M. B. C. (2012). Intergenerational Poverty Dynamics in Poland: Family Background and Children's Educational Attainment During Transition. Discussion Paper No. 02-34 Intergenerational, 1(02), 234- 567.

[25]. McDermott, R., \& Vossoughi, S. (2020). The culture of poverty, again. Diaspora, Indigenous, and Minority

[26]. Education, 14(2), 60-69. https://doi.org/10.1080/15595692.2020.1733960

[27]. McLeod, S. (2013). "Maslow's Hierarchy of Needs". Highgate Counselling Centre. Retrieved from http://highgatecounselling.org.uk/members/certificate/CT2\%20Paper\%201.pdf.

[28]. Mensah, F. K., \& Kiernan, K. E. (2010). Gender differences in educational attainment: Influences of the family environment. British Educational Research Journal, 36(2), 239-260. https://doi.org/10.1080/01411920902802198

[29]. Munir Kayani, M., Akbar, R. A., Faisal, S., Kayani, A., \& Amin Ghuman, M. (2017). Analysis of SocioEconomic Benefits of Education in Developing Countries: A Example of Pakistan. Bulletin of Education and Research, 39(3), 75-92.

[30]. Pender, J., Pender, J., Marré, A., \& Reeder, R. (2019). Concepts, Strategies, and Measures. Economic Research Services, 1(12), 56-65.

[31]. Sackey, H. A. (2017). The Determinants of School Attendance and Attainment in Ghana: A Gender Perspective (Issue 1).

[32]. Sánchez, P. A., Rodríguez, R. D. H., \& Maldonado, R. M. (2019). Barriers to Student Learning and Participation in an Inclusive School as Perceived by Future Education Professionals. Journal of New Approaches in Educational Research, 8(1), 18-24. https://doi.org/10.7821/naer.2019.1.321

[33]. Schultz, (2016). Gender and its Relevance to Macroeconomic Policy: A Survey. IMF Working Papers, 06(233), 1. https://doi.org/10.5089/9781451864939.001

[34]. Spitzer, C., Klauer, T., Grabe, H.-J., Lucht, M., Stieglitz, R.-D., Schneider, W., \& Freyberger, H. J. (2013).

[35]. Gender Differences in Dissociation. Psychopathology, 36(2), 65-70. https://doi.org/10.1159/000070360

[36]. Swinnerton, K. A. (2016). How do adult returns to schooling affect children's enrollment? Raising future expected monetary gains to schooling and poor families'. US Department of Labor, and IZA, Germany, 1(10), 1-11. https://doi.org/10.15185/izawol.305

[37]. Tom, (1997). Examining the Relationship Between. Individual Differences Research, 2(90), 370-374.

[38]. Voituriez, T., Morita, K., Giordano, T., Bakkour, N., \& Shimizu, N. (2017). Financing the 2030 agenda for sustainable development. Governing Through Goals: Sustainable Development Goals as Governance Innovation, 16301(10), 259-273. https://doi.org/10.1057/978-1-137-45443-0_24

[39]. Voyles, M. (2011). Student academic success as related to student age and gender. Unpublished Master's Thesis, 2(1), 111.

[40]. Washbrook, E., Gregg, P., \& Propper, C. (2014). A decomposition analysis of the relationship between parental income and multiple child outcomes. Journal of the Royal Statistical Society. Series A: Statistics in Society, 177(4), 757-782. https://doi.org/10.1111/rssa.12074

[41]. World Bank Group. (2015). Public Expenditure Review of the Education Sector in the Democratic Republic of Congo. An Efficiency, Effectiveness, and Equity Analysis. World Bank Education, 1(Report No. ACS14542). 
[42]. Yao, R., Adzido, N., Dzogbede, O. E., Ahiave, E., \& Dorkpah, O. K. (2016). Assessment of Family Income on Academic Performance of Tertiary Students: The Case of Ho Polytechnic, Ghana. International Journal of Academic Research in Accounting, Finance and Management Science, 6(3), 154-169.

[43]. https://doi.org/10.6007/IJARAFMS/v6-i3/2221 